\title{
MICROLEVEL STUDY FOR THE ASSESSMENT OF THE ECONOMIC IMPACT OF RESISTANCE TO DISINFECTANTS USED IN THE HOSPITAL ENVIRONMENT AND EVALUATION OF NEW ALTERNATIVES
}

\footnotetext{
Assoc. Prof. Dr. Mariana-Carmen CHIFIRIUC, University of Bucharest, Faculty of Biology, Microbiology Immunology Department, carmen_balotescu@yahoo.com

Biol. Dr. Mihaela Magdalena MITACHE, Institute of Public Health, Constanta, Romania, magdamitache@yahoo.com

Biol. Alina BADEA, University of Bucharest, Faculty of Biology, Microbiology Immunology Department, bd_alina@yahoo.com

Biol. Oana Livia GEANA, University of Bucharest, Faculty of Biology, Microbiology Immunology Department, oanalivia_geana@yahoo.com

Assoc. Assist. Marcela BUCUR, University of Bucharest, Faculty of Biology, Microbiology Immunology Department, bmarcelica@yahoo.com
}

Assoc. Prof. Dr. Rodica OLAR, Mihaela BADEA, University of Bucharest, Faculty of Chemistry, Department of Inorganic Chemistry, rodica_m_olar@yahoo.com

Assoc. Prof. Dr. Mihaela BADEA, University of Bucharest, Faculty of Chemistry, Department of Inorganic Chemistry, Bucharest, Romania, mbadea@yahoo.com

Dr. Paul IONESCU, Public Health Authority, paulionescu@yahoo.com

Prof. Tatiana SESAN, University of Bucharest, Faculty of Biology, Muycology Department, sesan@botanic.unibuc.ro

Veronica LAZAR, University of Bucharest, Faculty of Biology, Microbiology Immunology Department, lazar@botanic.unibuc.ro 


\begin{abstract}
Introduction. The emergence of the antibiotic resistance and multi-resistance to antibiotics drives the acute necessity for the developing of new anti-infective strategies and the permanent changes of the disinfectants used in the hospital environment. The purpose of this study was to investigate by adapted disk diffusion techniques the antimicrobial potential of six (6) newly synthesized chemical compounds (derivatives from phenantroline and cooper complexe combinations with dimethylguanidine), 5 usual disinfectants (Oxigenon, Combi instruments, Virkon, Biguacid, Big spray) and 13 newly synthesized chemical compounds with potential disinfectant activity against 100 enterobacterial strains isolated from different surfaces in the hospital environment grown in planktonic and adherent form, in order to select the most appropriate alternative based on a good cost-effectiveness ratio.
\end{abstract}

Methods: The initial qualitative screening of the antimicrobial activity was performed by disk diffusion and the minimal inhibitory concentration (MIC) of the active chemical compounds was established by Mueller Hinton broth microdillution method using 96-multiwell plates. The microbial strains were tested for their adherence capacity and biofilm developing potential on inert substrata (quantified by a simple method consisting in growing the microbial strains in 60-multiwell plates for 24 hours at $37 \mathrm{C}$ degrees and the biofilms formed on the wall was fixed by methanol and stained by violet crystal and the intensity of color was quantified by measuring the absorbance at $490 \mathrm{~nm}$ by an ELISA reader).

Results: The 100 enterobacterial strains isolated from surfaces in the hospital environment exhibited high resistance rates to cephuroxime $(100 \%)$, cephtazidime (100\%), ampicillin (98\%), cefoxitin (98\%), ticarcillin (62\%), amoxicillin/ clavulanic acid (53\%). $36 \%$ of these strains were confirmed for the production of ESBLs and $50 \%$ exhibited AMPc inducible beta-lactamases. All tested strains also exhibited high level resistance to tetracyclines (46-53\%) and trimetoprim/sulphametoxazole. Concerning their susceptibility to usual disinfectants, the tested strains exhibited high resistance to Oxigenon and to Virkon and were susceptible to Biguacid, Big spray and Combi instruments, the last one being the most effective, active at low concentrations against all tested enterobacterial strains. Concerning the newly synthesized compounds, they exhibited a very low antimicrobial activity. The six derivatives from phenantroline and cooper complexe combinations with dimethylguanidine exhibited antimicrobial activity against the majority of the tested strains with MIC values ranging from 18 to $625 \mu \mathrm{g} / \mathrm{ml}$. The subinhibitory concentrations of the tested chemical compounds slightly inhibited the adherence capacity of the tested strains to the inert substratum. Conclusion. Our results are demonstrating that the increasing rates of resistance to antibiotics in enterobacterial strains are correlated with increasing rates of resistance to the disinfectants used in the hospital environment, as a results of adaptation of an existing resistance mechanism to multiple antimicrobial substrates. The phenantroline derivatives 
MICROLEVEL STUDY FOR THE ASSESSMENT OF THE ECONOMIC IMPACT OF RESISTANCE TO DISINFECTANTS USED IN THE HOSPITAL ENVIRONMENT AND EVALUATION OF NEW ALTERNATIVES could represent a novel strategy for the antimicrobial treatment, besides the bactericidal effect, the subinhibitory concentrations of newly synthesized chemical compounds impairing the microbial adherence capacity to the inert substratum.

Key Words: disinfectants, newly synthesized compounds

\section{INTRODUCTION}

The increase of the selective pressure of antibiotics and antimicrobial substances in the hospital environment led to the selection of multiresistant bacterial strains both in opportunistic, nosocomial agents and also in classical pathogens. It is also known that the resistance genes occurred in the microbial strains isolated from the hospital environment are of an older origin, originating in the external medium, evolving as non-specific defense mechanisms against the toxic compounds existing in the environment, such as plant metabolites and soil microbiota $(1,2)$. The emergence of the antibiotic resistance and multiresistance to antibiotics drives the acute necessity for the developing of new anti-infective strategies and the permanent changes of the disinfectants used in the hospital environment (3). The purpose of this study was to investigate the antimicrobial potential of six (6) newly synthesized chemical compounds (derivatives from phenantroline and cooper complexe combinations with dimethylguanidine), 5 usual disinfectants (Oxigenon, Combi instruments, Virkon, Biguacid, Big spray) and 13 newly synthesized chemical compounds with potential disinfectant activity against 100 enterobacterial strains isolated from different surfaces in the hospital environment grown in planktonic and adherent form, in order to select the most appropriate alternative based on a good cost-effectiveness ratio.

\section{MATERIAL AND METHODS}

The microbial strains were isolated from different surfaces from the hospital environment all along the year 2006 and identified by aid of TSI (triple sugar iron), MILF (mobility, indole production, lysin decarboxilase, phenylalanindesaminase) MIU (mobility, indole production, urease production), Simmons (citrate use as carbon source) biochemical screening tests and miniAPIsystem $(4,5)$. The initial qualitative screening of the antimicrobial activity was performed by spotting $5 \mu \mathrm{l}$ of the chemical compound solubilised in Dimethyl-phormamide $(10 \mathrm{mg} / \mathrm{mL})$ on Mueller Hinton medium previously seeded with microbial suspensions. The minimal inhibitory concentration (MIC) of the active chemical compounds was established by broth microdillution method using 60-multiwell plates. The microbial strains were tested for their adherence capacity and biofilm developing potential on inert substrata (quantified by a simple method consisting in growing the microbial strains in 60-multiwell plates for 24 hours at 37 Celsius degrees and the biofilms formed on the wall was fixed 
by methanol and stained by violet crystal and the intensity of color was quantified by measuring the absorbance at $490 \mathrm{~nm}$ by an ELISA reader) (6-11). The influence of the chemical compounds on the biofilm developing potential was tested by the same method with the specification that the microbial cultures were grown in the presence of subinhibitory concentrations of the tested compound solubilised in DMF for 24 hours.

\section{RESULTS AND DISCUSSION}

The biochemical identification of the tested strains revealed their affiliation to Enterobacteriaceae family, the majority of the tested strains belonging to $E$. coli, followed by Klebsiella sp. (K. oxytoca, K. pneumoniae and Enterobacter cloacae). All six chemical compounds exhibited antimicrobial activity against the majority of the tested strains, as revealed by the growth inhibition zones occurred around the solution spots. The complex combinations of phenantroline derivatives exhibited superior antimicrobial activity demonstrated by the low MIC values (ranging from 18-156 $\mu \mathrm{g} / \mathrm{ml}$ ), comparatively with the combinations of $\mathrm{Cu}$ $\mathrm{N}, \mathrm{N}$ dimethyl-biguanidine with higher MIC values to $625 \mu \mathrm{g} / \mathrm{ml}$. Our results showed that the subinhibitory concentrations of the tested chemical compounds slightly inhibited the adherence capacity of the tested strains to the inert substratum, excepting the cooper complex combination with dimethylbiguanidine that stimulated the bacterial adherence. All the $\mathrm{Cu}$ phenantroline compounds inhibited the bacterial adhesion to the inert substrate and implicitly the development of biofilms, while the combinations of the copper ions with the dimethyl-biguanidine did not exhibited this activity. So the use of phenantroline compounds could represent an alternative to the disinfectant substances used until present, useful in combating the contamination of the materials and the reduction of the infection risk with multi resistant bacteria and with potential of biofilms formation. Concerning their susceptibility to usual disinfectants, the tested strains exhibited high resistance to Oxigenon and to Virkon and were susceptible to Biguacid, Big spray and Combi instruments, the last one being the most effective, active at low concentrations against all tested enterobacterial strains. Concerning the newly synthesized compounds, they exhibited a very low antimicrobial activity.

\section{CONCLUSION}

The present study showed that the entrobacterial strains isolated from different surfaces in the hospital environment exhibited high levels resistance to usual disinfectants, outlining for the investigation of new compounds with disinfectant activity. Our results demonstrated that none of the new disinfectant substances exhibited good antimicrobial activity; in exchange a good antimicrobial potential was observed for some derivatives of phenantroline and $\mathrm{N}, \mathrm{N}$-dimetilbiguanidine against enterobacterial strains isolated from various surfaces in the hospital environment, both on planktonic cells and adherent bacteria. 
MICROLEVEL STUDY FOR THE ASSESSMENT OF THE ECONOMIC IMPACT OF RESISTANCE TO DISINFECTANTS USED IN THE HOSPITAL ENVIRONMENT AND

\section{SELECTIVE REFERENCES}

ANDREMONT, A. (1987) : «Infections sur materiel d' infusion parenterale prolongee », Medicine et maladies infectieuses , 323-325

ANDREMONT, A. (1990) : "Ecosisteme intestinal et antibioterapie », La Lettre de l'Infectiologue. Tome V , 100-103

ANGELESCU, M. (1998) : "Antibiotic therapy », Bucureşti, Editura Medicală LAZAR, V. (2003): „Microbial adherence”, Editura Academiei Române,

Bucureşti.

LAZAR, V.; CERNAT, R.; BALOTESCU, M.C.; HERLEA, V.; BULAI, D. and MORARU, A. (2004): "General microbiology (practical works manual)", Bucureşti, Editura Universităţii din Bucureşti.

OLAR, R.; BADEA, M.; CRISTUREAN, E.; LAZAR, V.; CERNAT, R. and BALOTESCU, M.C. (2005): „Thermal behavior, spectroscopic and biological characterization of $\mathrm{Co}$ (II), $\mathrm{Zn}$ (II) and $\mathrm{Pt}$ (II) complexes with $\mathrm{N}, \mathrm{N}$ dimethylbiguanide", J. Thermal Analysis and Calorimetry, 80: 451 - 455.

LAZAR, V.; BALOTESCU, M.C.; MOLDOVAN, L.; VASILESCU, G.; PETRACHE, L.M.; BULAI, D. and CERNAT, R. (2005): „Comparative evaluation of qualitative and quantitative methods used in the study of antifungal and antibacterial activity of hydroalcoholic vegetal extracts", Roumanian Biotechnological Letters, 10: 2225-2232

BALOTESCU, M.C.; OPREA, E.; PETRACHE, L.M.; BLEOTU, C. and LAZAR, V. (2005): „Antibacterial, antifungal and cytotoxic activity of salvia officinalis essential oil and tinctures", Roumanian Biotechnological Letters, 10: 2481-2481

*** Performance Standards for Antimicrobial Susceptibility Testing; Seventeenth Informational Supplement, M100-S17, Vol. 27 No. 1, Replaces M100-S16, Vol. 26 No. 3, Informational Supplement 2007

BALOTESCU, M.C.; LIMBAN, C.; MISSIR, A.V.; CHIRITA, I.C. and NITULESCU, M.G. (2007): „The Synthesis and Biological Activities Of Some New 2-(4-Methoxy-phenoxymethyl) benzoic Acid Thioureides", Revista de Chimie (Bucuresti), 58: 1064 -1068

Brown, M.R.W. and GILBERT, P. (1993): „Sensitivity of biofilms to antimicrobial agents", J. Appl Bacteriol.-Symp. Suppl.:"Microbial cell envelopes: interactions and biofilms" (Quesnel, L.B. Gilbert, P., Handley, Pauline S., eds.), Oxford, Blacwell Scient. Public, 74:87S-97S 